\title{
Review
}

\section{The Importance of Seawater Intake and its Treatment Techniques for RO Desalination Plant}

\author{
Ahmad Hussain ${ }^{a *}$, Iqbal Ahmed ${ }^{\mathrm{b}}$ and Mahrukh Mahrukh ${ }^{\mathrm{c}}$ \\ ${ }^{a}$ Department of Mechatronics Engineering, Shaheed Zulfiqar Ali Bhutto Institute of Science \& Technology \\ (SZABIST), Karachi, Pakistan \\ bepartment of Mechanical Engineering, King Abdulaziz University, P.O. Box 80200, Jeddah 21589, \\ Saudi Arabia \\ ${ }^{\mathrm{c}}$ Department of Mechanical Engineering, NED University of Engineering \& Technology, Karachi, Pakistan
}

(received July 30, 2018; revised March 13, 2019; accepted March 15, 2019)

\begin{abstract}
Seawater intake and its treatments are one of the main upstream processes of every seawater desalination plant (RO, ED, MSF, MED). However, the process has turned out to be of utmost importance for reverse osmosis (RO) desalination plant. It is to be sure that sufficient and steady flow and quality of water is available to the RO desalination plant. Prior to RO feed water, the seawater intake pre-treatment process has to be tailored and the quality of seawater intake to be treated either subsurface intake or open surface intakes, particularly when treating open surface intakes seawater (OSIS) with exceedingly unpredictable quality. According to the well-established membrane manufacturer and supplier, the RO membrane warranty and guarantee are depended on seawater intake quality and its pre-treatment. Thus, the current state-of-the-art RO membranes life and performance success for desalination processing depend upon OSIS pre-treatment processing techniques. This article is emphasizing an overview on recent OSIS and its pre-treatment techniques for RO desalination plant.
\end{abstract}

Keywords: desalination, reverse osmosis, pre-treatment, seawater intake, OSIS techniques

\section{Introduction}

Momentous regions of the humankind are suffering an unrivalled escalation in population, in the criterions of living and industrial growth. Globally fresh water supplies become progressively more stressed while global population continues to grow. At this point, the seawater desalination has turned out to be an option for new water availability in the coastal areas. Today, over 18,426 desalination plants operate in more than 150 countries worldwide, producing drinking water about 22.9 billion US gallons by either utilizing brackish water with a salt substance of lesser than $10,000 \mathrm{mg} / \mathrm{L}$ or seawater which saltiness in a scope of 30,000 to $44,000 \mathrm{mg} / \mathrm{L}$. Figure 1 shows a worldwide installed desalination plants. Desalination produces about $1 \%$ of the global freshwater; however, this amount is increasing every year. An expected 10 billion USD hypothesis in next five years would include 5.7 million cubic meters for each day of current generation limit. This capacity is going to increase twofold by 2030 . Without a doubt,

\footnotetext{
*Author for correspondence;

E-mail:ahmad.hussain@szabist.edu.pk
}

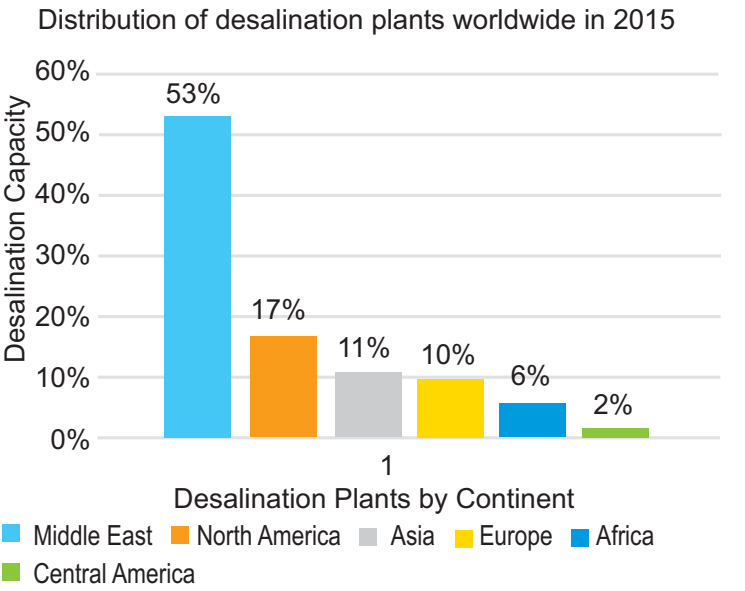

Fig. 1. Recent scenario of installed desalination plants global regions (Statista, 2015)

a few nations, for example, Spain, Saudi Arabia, and the United Arab Emirates, now depend on desalinated water for over $70 \%$ of their water supply. Macedonio et al. (2010) reports that warm desalination is considered as a preferable source of fresh water in the Gulf 
Cooperation Council (GCC) due to abundance of petroleum derivative in this region. $\mathrm{RO}$ film has now driven the warm procedures in new plant establishments because of lesser vitality usage $\left(2.2-6.7 \mathrm{kWh} / \mathrm{m}^{3}\right)$, higher recuperation factor $(\sim 40-60 \%)$ and substandard desalted water costs $\left(0.50-0.70 \$ / \mathrm{m}^{3}\right)$. The reality the measurements demonstrate that film and warm procedures are similarly sharing generation limit, with RO ruling the layer forms and multi-organize streak (MSF) overseeing warm procedures. The critically huge deviation is concerned with the activity of seawater with lacking saltiness. This also involves the element of temperature, and the hot storm cellar water which requires the utilization of cooling water frameworks which can bring their issues. Consequently, when these film frameworks are further divided, it creates huge inconvenience. Thus, to overcome the fouling problems, the design of the system should be improved along with the seawater intake, standardised pre-treatment strategies and improved procedures of maintenance (Fig. 2).

RO desalination requires new membrane materials and scientific techniques for both the seawater intake and pre-treatment of such waters along with the rich fouling so that they can be composed adequately for the RO process. The RO membrane technology also needs to be improved so that the membranes produced become less susceptible to failures when they are put for pretreated lower quality feeds (Al-Ahmad et al., 2000; Redondo, 1999). In the influent feed water, the primary to dense element configuration is a susceptibility to

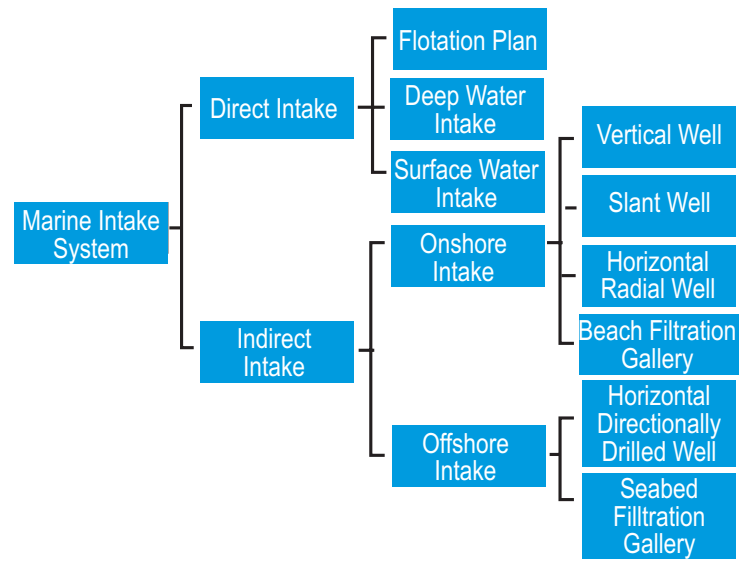

Fig. 1. Classification of seawater intake systems for desalination plants (Pacific Institute, 2013). foul from those matters that are suspended. This is to be done along with the predominantly microbiological type. A number of research studies have pointed out that when the RO membranes undergo microbial fouling, the membrane surfaces assign the beginning of the development of biofilm to the early molecular adhesion of biological matters to those membrane surfaces having thin film composite (TFC) (DCC, 2017; 2014; 2002; Ayache et al., 2013; Missimer et al., 2013).

The following major parameters of the membrane systems have been identified.

- Source and types of seawater intake,

- types of marine organisms (macro- and microorganic) components,

- the affinity of membrane surface,

- membrane chemistry and structure,

- operating parameters (feed pressure, temperature, time, permeate, rejection),

- product yield,

- dispense of accessible nutrients,

- desalinated water pre-treatment,

- the presence of inorganic particulates,

- storage of fresh water,

- other site-specific conditions.

Before installing any desalination process (thermal or membranes), the analysis of the geological survey, impingement and entrainment and selection of the side of seawater intake, respectively is vital. When any desalination process (polymeric $\mathrm{RO}$ membrane including RO, FO, PRO, ED, MD, MED, MSF) is studied, it is imperative to ensure the adequacy of seater in both qualitative and quantitative terms from the OF type that is setup downstream (Gille, 2003).

Moreover, the type and reliability of seawater intake is not only a significant factor for the desalination plant but it is also equally crucial for power plant coolant. As an initial stage, before defining the mainly appropriate kind of seawater intake, it is compulsory to classify the necessities for the related type of desalination plant. Table 1 summarized that the MSF technology is a very robust technology with least dependence on the particle sizes allowed to enter the desalination plant. The MED facility needs strict particle filtration for the water flowing into the condenser tubes and excellent filtration for the seawater going through the spray nozzles. The RO membrane facility necessitates a good seawater quality that it cannot be measured only in particle size. Therefore, extra parameters, like the feed water post- 
Table. 1 Quality and quantity of Inflowing particle size of different desalination processes (Gille, 2003).

\begin{tabular}{|c|c|}
\hline Desalination process & Inflowing particle size \\
\hline Multi-stage flash (MSF) & $\begin{array}{l}3.33 \text { of tube inner } \\
\text { diameter }=5 \mathrm{~mm} \text { for } \\
15 \mathrm{~mm} 1 \text { tubes to } 15 \mathrm{~mm} \\
\text { for } 45 \mathrm{~mm} \text { tubes }\end{array}$ \\
\hline $\begin{array}{l}\text { Multi effect } \\
\text { desalination (MED) }\end{array}$ & $\begin{array}{l}3.33 \text { of inner diameter of } \\
\text { condenser tubes }=4 \mathrm{~mm} \text { for } \\
12 \mathrm{~mm} \text { tubes to } 8 \mathrm{~mm} \text { for } \\
24 \mathrm{~mm} \text { tubes }+0.5 \mathrm{~mm} \\
\text { for spray nozzles }\end{array}$ \\
\hline $\begin{array}{l}\text { Multi effect vapor } \\
\text { desalination (MEV) }\end{array}$ & $\begin{array}{l}3.33 \text { of inner diameter of } \\
\text { condenser tubes }=4 \mathrm{~mm} \text { for } \\
12 \mathrm{~mm} \text { tubes to } 8 \mathrm{~mm} \text { for } \\
24 \mathrm{~mm} \text { tubes }+0.5 \mathrm{~mm} \\
\text { for spray nozzles }\end{array}$ \\
\hline $\begin{array}{l}\text { RO membrane including } \\
\text { Forward-osmosis (FO), } \\
\text { pressure retarded osmosis } \\
\text { (PRO), electrodialysis (ED) }\end{array}$ & $5-20 \mu \mathrm{m}+$ SDI value $<3.5$ \\
\hline
\end{tabular}

treatment, SDI value have to be utilized for the seawater flowing into the $\mathrm{RO}$ membranes.

Two types of desalination plant in the seawater intakes are taken into consideration, viz. direct and indirect intakes. This review provides a summary of these two types and the correlation that exists with reference to the seawater intakes. Direct seawater intakes (DSI) also assigned to as open water intakes pull out seawater directly from the sea. It is important to identify that the DSI may be witnessed at the surface or in the deep water; however, they are less frequently found on a floatation plant. A number of desalination plants utilise the surface intake system for the DSI. This involves a unit of intake screens that constantly removes the debris, marine life and trash during the intake. A conveyance pipeline along with a wet well or similar such mechanisms are commissioned for housing the pumps. This system also suggests that for the DSI to function, there has to be pre-treatment system, especially in the case of RO desalination plant.

The drawback of DSI include the disturbance created for the marine organisms through marine encroachment and entrapment of seawater intake. However, these drawbacks vary for different desalination plants since the presence of marine life also varies based on the location. Hence, it needs the requirement to remove elements like dissolved organic carbon and the likes, silt and algae since they tend to clog the film membrane
(WASC, 2011). In a typical surface intake, submarine pipelines are installed on the sea bottom. These pipelines are stretched to a hundred or even thousands of meters from the coast. Additionally, permit wells with draws in more profound water and pipelines introduced on a dock, or an open passing on channel worn between barriers, significantly affects beach front and marine condition and should be mindfully considered to limit it (Peters and Pints, 2008). This additionally applies for the frameworks, where the water is removed from preserving water at power control stations. The desalination plants are fed with surface water and pump from the sea in depths of 1-6 $\mathrm{m}$ which is highly polluted with sand, fish, seaweed, algae, jellyfish, and microorganisms. Indeed, better seawater quality can be taken out from the depth below 35 meters because the wreckage load in such pits is by at least 20 times smaller than in surface water, and therefore it is practically clean. Additionally, this water is much cooler which increases the efficiency of all thermal desalination processes. Bar screens usually afford a first step of pretreatment for both thermal and membrane desalination plants by taking away debris, and large diameter total suspended solids from seawater. Several customized types of screens can be used for open ocean intakes structures including traveling water screens, mechanically cleaned bar screens, and good passive screens (DESALDATA, 2019). Screen chambers can be located offshore, onshore, or near shore. Utilizing more progressive screening techniques can enhance water quality and reduce the consequences of impingement and entrainment (T W D B, 2004).

Figure 3-4 show typical traveling water screens and mechanically cleaned bar screens and are most commonly used in DSI for medium and large sized desalination plants. Voyaging screens are outfitted with spinning wire work boards that turn through the water and are cleaned by a heavy water shower (Figure 3). The screens are deliberate to stop debris from inflowing the system instead of minimizing impingement and entrainment. The screens can be situated onshore, at the close of a passage or forebay that enlarge out with the region of breaking waves, or at the other or rear end of a pipe that is put into the sea, hence terminating in a vertical "velocity cap" inlet.

The entrance of the bar screen is commonly constituted of the bars of 20 to $150 \mathrm{~mm}$. This is followed by other small-sized, yet excellent, screens, having the openings of 1 to $10 \mathrm{~mm}$ (Fig. 3). This configuration prevents the 


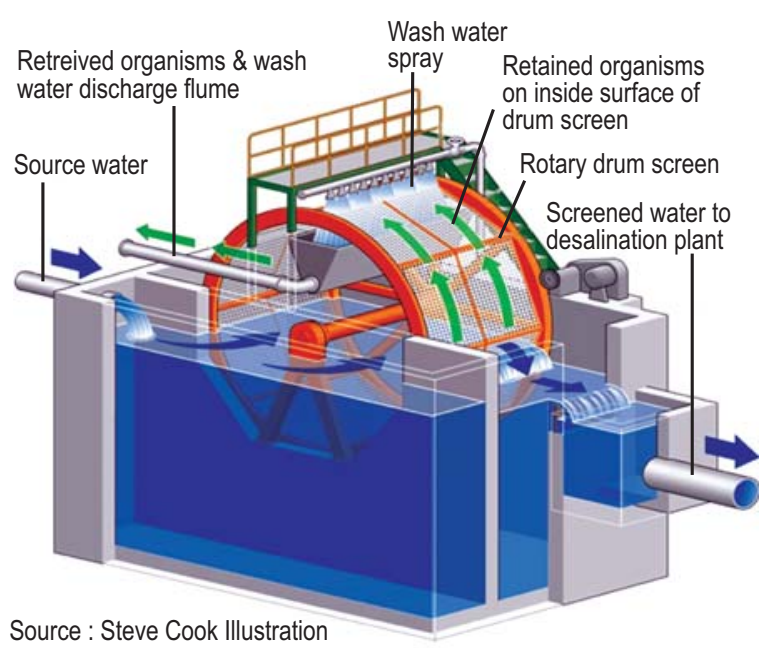

Fig. 3. Illustration of DSI bar screen (Water Filtration Infographic, 2019).

inflowing of most of the marine elements termed as mature and juvenile, such as fish and crab through the pipe into the desalination plant. In this regard, it is significant to note that the coarse screens at the entrance of the bar area are usually static, whereas the fine screens may come in two different configurations, i.e. static (passive) and moving (rotation in periods). Figure 3 highlights a fine screen moving (rotating) film. In this case, most marine life collected in this established procedure is commonly eliminated through the screening method. The lower stream filtration also removes the salt. Following the screening, the water is made to pass through some finer filters in order to pre-treat the seawater; these filters usually have sizes of the filtration media, usually ranging between the size (pores) of 0.01 microns to 0.2 microns for membrane ultrafiltration

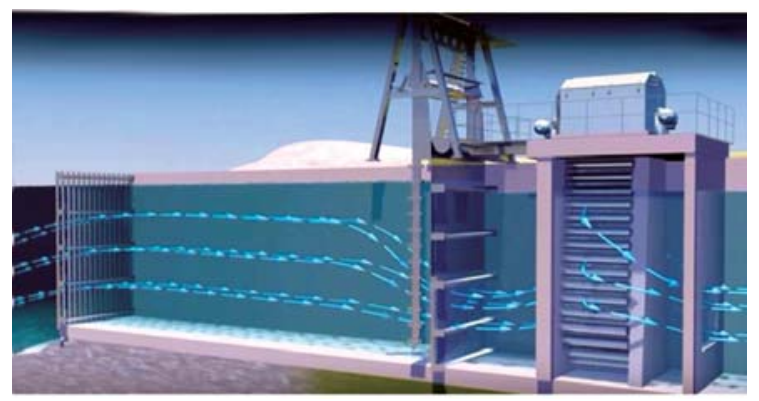

Fig. 4. Illustration of DSI bar screen (Jabal Ali Power and Desalination Plant, 2013). and microfiltration and 0.25 to $0.9 \mathrm{~mm}$ for granular media filters (water filtration infographic. 2019).

Passive screens are frequently used for small and moderate size desalination facilities. Current development in passive screen structure, including cylindrical wedge wire screens, allow large volume water intake at low speed and physically keeping out of marine lives with screen work sizes going from 0.5$10 \mathrm{~mm}$ (Fig. 5). Here pump shafts are used to connect them with the intake screens, or the pumps are associated with the intake screens by stretched-out pipelines. Passive screens are prime to be fitted for regions where normal cross-flow current is present. To accumulate the debris, it is recommended to use an air backwash system. This allows the clearing of screen and so the screen surface also remains clear from the debris.

Indirect seawater intake (subsurface intakes). The horizontal and vertical beach wells are important elements in the Indirect Seawater Intake (ISI). This setup also involves the infiltration galleries and the seabed filtration system. Thus, the seawater is collected by the subsurface intakes. Consequently, this allows for the pre-treatment of the seawater. This pre-treatment is done through a slow filter process and the ocean floor in this process is opted to be steady. The utilisation of subsurface intake takes place where the geologic circumstances beneath the surface water are practically resistant and having adequate depth and thickness. This is significant to support the water intake. In this

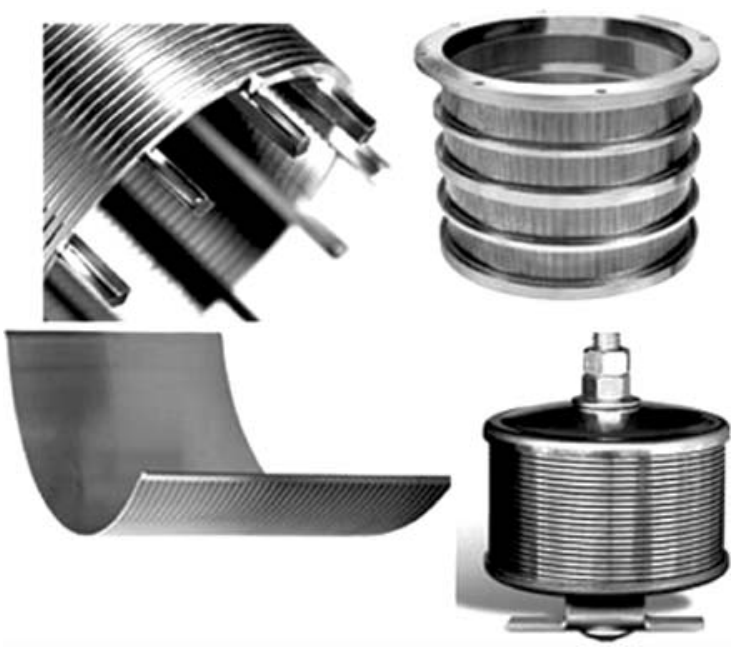

Fig. 5. Cylindrical wedge wire screens (Wedge Wire Screen, 2017). 
arrangement, most of the marine organisms from the water intake are naturally filtrated. However, in some instances, ISI may be estimated and controlled as groundwater sources. ISI has a number of advantages in the perspective of environment since the ecological impact is connected with the impingement and entrainment of marine organisms is largely avoided. ISI structure ought to consider their potential negative effect on close-by crisp groundwater aquifers.

The generally known aberrant intake strategy is the shoreline well admission (BWI). In this strategic setup, the seawater is diverted from the sand under the shoreline and thus lowering the seabed that happens to be close to the shore. Figure 6 demonstrates a design of vertical BWI framework. Normally, BWI is going about as a channel and in this way enhancing the mechanical nature of seawater and for the end of marine biodiversity and other contamination, present in the open seawater intakes. Furthermore, the collection of the seawater traditionally takes place in the wells. The seawater is then pumped to the plant. It can also be said that the seawater is then gathered in the level wells screens as these screens are connected with a vertical well that is again connected to a pump.

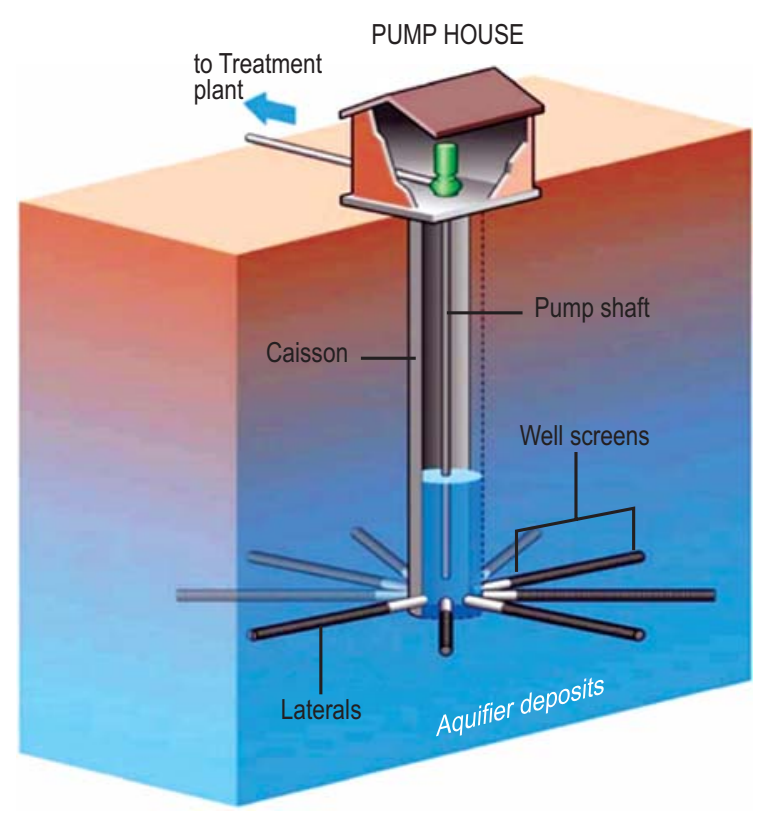

Fig. 6. Illustration of subsurface beach well water intake system (Water Globe Consulting, 2010).
As the geographical strata is constantly changing for several reasons, shoreline wells cannot be developed all over the place, and thus the utilisation of an open intake from the historical experiences appear to be the main viable path. The development of a roundabout admission by shoreline well has no marine natural effect amid operation, however may aggravate the earth amid development and a short time later with establishments like pump houses or front of accumulation wells on the shoreline or close-by.

The submerged slow sand media filtration system, more commonly referred to as the subsurface infiltration gallery intake system, and are located at the base of the deep-sea in the near shore surf zone also accommodate the ISI facilities. This seawater consumption framework is connected to an arrangement of admission wells put on the shore. Along these lines the ocean bottom must be exhausted to introduce the admission funnelling of the wells, being these channels hid at the base of the ocean depths in uncovering troughs. The greatness and built utilizing an indistinguishable essential from moderate sand channels, these frameworks are amassed utilizing much sheet-like level stone, shake strewn, replaced sand and unique sand. Figure 7 delineated the submerged moderate sand media filtration framework. The downside of ISI is for a situation of assembles source water from an alluvial aquifer. Notwithstanding, such water potentially will have low oxygen fixation. Likewise, this could contain the abnormal state of manganese, press, hydrogen sulphide, and other undesirable materials that can set back desalination plant switch osmosis (RO) film execution, water creation expenses, and release water quality. The establishment of such a seabed channel for the supply of seawater for greater desalination plants will bring about an extremely huge effect. Additionally, the marine widely varied vegetation in this area and on the encompassing environmental condition including the shoreline, as this framework additionally requires establishments for gathering the admission water before replacing it to the seawater desalination plant for facilitating action.

Dissolved air flotation (DAF). Air flotation, the DAF system, has established to be a successful membrane pre-treatment system, given that a multi-barrier concept to the treatment design, enhance membrane flux rate, minimize membrane maintenance and improve membrane life. Typically, DAF process is economical, and its footstep is much lesser as compared to conventional settling basins. Thus, in desalination 


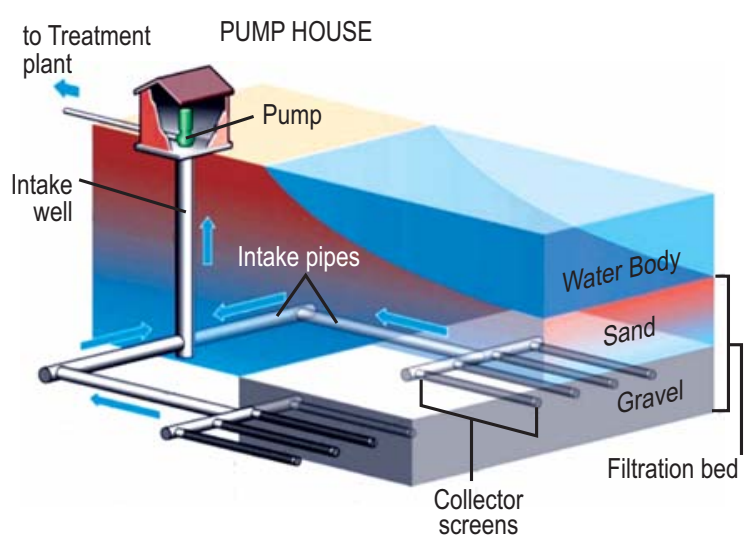

Fig. 7. Illustration of submerged slow sand media filtration system (Water Globe Consulting, 2010)

applications, right after the seawater intake the DAF pre-treatment process is identified for its tendency to significantly detach algae and other low-density solids from seawater (Water World, 2013), DAF is a substitute clarification process that employs micro air bubbles to fix and drift small clumps pieces and suspended solids to the water surface for removal and Fig. 8 shows a typical well-established DAF process. In comparison, sedimentation removes settled solids from the bottom. The pilot and full-scale DAF technologies have established their capacity to offer active seawater treatment throughout hazardous algal blooms (HABs) events over the past five years (Churman and Henthorne, 2013). It was also reported that in the late 2008 a rigorous, unrelenting red tide incident occurred along the coast of the UAE. It shows the incident of over the course of the HAB in UAE. Figure 9 shows that several desalination plants were forced to shut down, including the Federal Electricity and Water Authority's (FEWA),

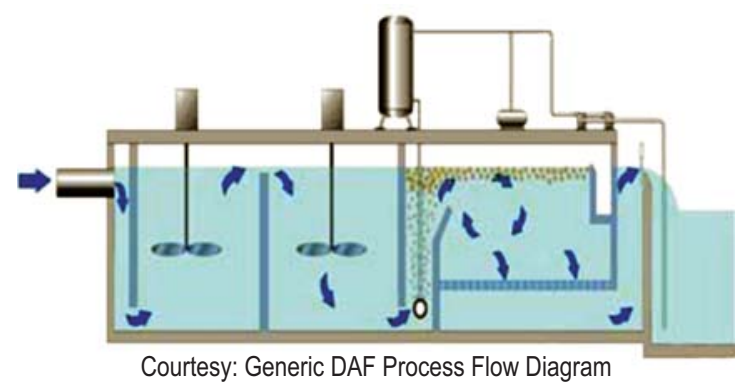

Fig. 8. A typical well-established DAF process (Water World, 2013).
Al Ghalilah SWRO plant, the Fujairah Fresh Water Company plant in Fujairah Port, Sharjah Electricity and Water Authority's (SEWA), Khor Fakkan SWRO plant, and Abu Dhabi Water and Electricity Authority's (ADWEA) Fujairah 1 facility (Youtube 2013).

SWRO membrane feed water pre-treatment process. In recent year several SWRO systems manoeuvre efficiently with traditional pre-treatment methods that are well deliberate, prolonged and managed and most of SWRO feed water pre-treatment system is operated by coagulation, flocculation, clarification, and filtration. SWRO feed water pre-treatment is very frequent in almost all GCC RO-systems using DSI (Shahalam et al., 2002).

Table 2 summarized the conventional chemical pretreatments and their applications. Table 3 demonstrates the amount of numerous chemicals that were utilized in pre-treatment of groundwater in Saudi Arabia.
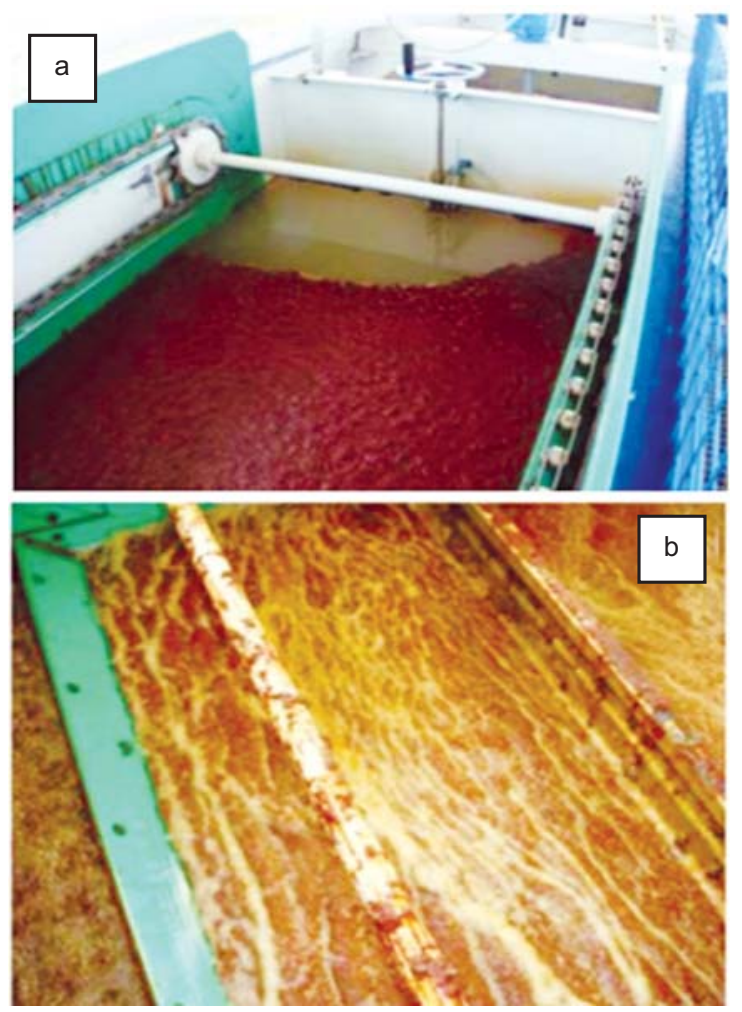

Fig. 9. Illustration of a case study of HABs effect after water intake and before pre-treatment (upstream process), (a) normal operating conditions; (b) red tide conditions (IDA, 2013). 
Table 2. Chemical compounds in SWRO feed water pre-treatment of GCC and their uses (Shahalam et al., 2002).

\begin{tabular}{ll}
\hline \hline Chemicals in pre-treatment & Remarks \\
\hline Chlorine gas $(\mathrm{Cl})$ & $\begin{array}{l}\text { To kill germs, virus, } \\
\text { algae etc. }\end{array}$ \\
Sodium bisulphite $\left(\mathrm{NaHSO}_{3}\right)$ & $\begin{array}{l}\text { To neutralize } \mathrm{Cl} \\
\text { To remove corrosive } \\
\text { Citric acid }\left(\mathrm{C}_{6} \mathrm{H}_{8} \mathrm{O}_{7}\right)\end{array}$ \\
$\begin{array}{l}\text { metals } \\
\text { Demove deposits }\end{array}$ \\
Tannic acid (polyphenol) & Improve rejection \\
Lutonol M40 (adhesive) & Improve rejection \\
Ammonium hydroxide $\left(\mathrm{NH}_{4} \mathrm{OH}\right)$ & pH adjustment \\
Caustic soda (NaOH) & pH adjustment \\
\hline \hline
\end{tabular}

Table 3. Chemical reagents amount (ppm) utilized in pre-treatment of ground water in Saudi Arabia (Shahalam et al., 2002).

\begin{tabular}{ll}
\hline \hline Chemical reagents & Amounts $(\mathrm{ppm})$ \\
\hline Sodium carbonate food grade $\left(\mathrm{Na}_{2} \mathrm{CO}_{3}\right)$ & $240-340$ \\
Calcium hydroxide $(\mathrm{CaOH})$ & $110-140$ \\
Sodium aluminate $\left(\mathrm{NaAlO}_{2}\right)$ & $12-1.5$ \\
Coagulation aid & 0.0220 .2 \\
\hline \hline
\end{tabular}

However, disturbance in the execution of a customary framework can prompt over the top levels of solids causing saline solution spacer stopping and expanded weight drop on the focus side of the film. On the off chance that chemicals overdose or the wrong chemicals are utilized as a part of regular pre-treatment, this can cause a permanent increase in the trans-membrane weight (TMP). Expanded power utilization, expanded compound cleanings and decreased film benefit life prompts higher RO framework working and upkeep costs. Membrane filtration systems, including microfiltration/ultrafiltration (MF/UF), are pre-treatment technologies that have the ability to remove TSS from seawater efficiently. Membrane filtration as pre-treatment to $\mathrm{RO}$ is used throughout the world and can protect RO membranes reliably with minimal energy consumption. UF and MF systems, in particular, have proven effective during HAB events. For example, during a pilot study in Hong Kong where Red tides occurred several times over two years, membrane filtration pre-treatment technologies maintained their recovery levels without signs of irreversible fouling. According to desalination experts, conservatively designed membrane filtration systems which operate at low fluxes may be sufficient for "all but the most severe blooms", and are considered superior to single or two-stage granular media filter alternatives (WWS, 2017; Statista, 2015; Cooley et al., 2013; WGC, 2010)

\section{Conclusion}

Seawater admissions framework either immediate or circuitous frame work or SWRO framework pretreatment of seawater, and in addition, the arrival of the reject water shaped in a desalination plant must be altered. The exact circumstances at the manufacturing site of both desalination (thermal or RO) plant, the approach of evaluation standard that chooses the unrivalled, available innovation and the best answer for the seawater admission and bolster water post-treatment and introduced a framework at a plant under discourse is necessary. In this manner, the utmost focuses with parallel an incentive as specialized points of interest are highlights related with the earth, to be measured in the manufacturing part and all through the long-haul operation.

\section{Acknowledgement}

The authors gratefully acknowledge the Centre of Excellence in Desalination Technology, Department of Mechanical Engineering, King Abdulaziz University for their help and for the kind moral support by providing platform, thus enabling us to carry out this study.

Conflict of Interest. The authors declare no conflict of interest

\section{References}

Al-Ahmad, M., Abdul, A., Mutiri, A., Ubaisy, A. 2000. Biofouling in RO membrane systems Part 1: Fundamentals and control. Desalination, 132:173179. ()

Ayache, C., Manes, C., Pidou, I.M., Croue, J.P., Gernjak, W. 2013. Microbial community analysis of fouled reverse osmosis membranes used in water recycling, Water Resources, 47:3291-3299.

Churman, H.J., Henthrone, L. 2013. Treating A Moving Target: Harmful Algal Blooms, International Desalination Association, IDA, White Paper, World Congress on Desalination and Water Reuse 2013, Tianjin, China.

Cooley, H., Ajami, N., Heberger, M. 2013. Key Issues in Seawater. Desalination in Colifornia: Marine Impacts. Retrieved from [Accessed: $13^{\text {th }}$ Nov 
2018].

DESALDATA, 2019. Retrieved from. [Accessed 13 Nov 2018].

DCC, 2017. FILMTEC ${ }^{\mathrm{TM}}$ Reverse Osmosis Membranes. Technical Manual. Retrieved from [Accessed: 12 Nov 2018].

DCC, 2014. Product Safety Assessment: Butyl Acrylate. Retrieved from [Accessed: 12 Nov 2018].

DCC, 2002. Technical Manual Colloidal Fouling Prevention. Dow. Chemical Company (Filmatech membrane): From No. 609-00307-702 QRP, July 2002.

Gille, D. 2003. Seawater intakes for desalination plants, Desalination, 156:249-256.

Macedonio, F., Drioli, E., Gusev, A.A., Bardow, A., Semiat, R., Kurihara, M. 2010. Efficient technologies for worldwide clean water supply, Chemical Engineering and Processing, 51:2-17.

Missimer, T.M., Ghaffour, N., Dehwah, A.H.A., Rachman, R., Maliva, R.J., Amy, G. 2013. Subsurface intakes for seawater reverse osmosis facilities: Capacity limitation, water quality improvement and economics. Desalination, 322: 37-51.

Peters, T., Pintó, D. 2008. Seawater intake and pretreatment/brine discharge-environmental issues, Desalination, 221:576-584.

Redondo, J.A. 1999. Improve RO system performance and reduce operating cost with FILMTEC fouling- resistant (FR) elements. Desalination, 126:249259.

Shahalam, A.M., Al-Harthy, A., Al-Zawhry, A. 2002. Feed water pretreatment in RO systems: unit processes in the Middle East. Desalination, 150:235-245.

Statista, 2015. Distribution of Desalination Plants Worldwide in 2015 by region. Retrieved from, [Accessed: $13^{\text {th }}$ Nov 2018].

TWDB, 2004. The Future of Desalination in Texas. vol 1, Biennial Report on Seawater Desalination. Texas Water Development Board, Texas, USA.

WASC, 2011. Desalination Plant Intakes, Impingement and Entrainment Impacts and solution. Water Reuse Association Desalination Committee White Paper Retrieved from. [Accessed: 13 Nov 2018].

Water Filtration Infographic, 2019. Retrieved from. [Accessed: $13^{\text {th }}$ Nov 2018].

Water World, 2013. Clarifying Treatment Dissolved Air Flaotation Provides Alternative Treating Raw Water with Light Particles. Retrieved from. [Accessed: 13 Nov 2018].

WGC, 2010. Evaluation of Alternature Desalinatin Plant Techical Memorandum Water Globe Consulting. Retrieved from. [Accessed: $13^{\text {th }}$ Nov 2018].

WWS, 2017 Wedge Wire Screen. Retrieved from, . [Accessed: $13^{\text {th }}$ Nov 2018].

Youtube, 2013. Jabal Ali Power and Desalination Plant. Retrieved from. [Accessed: 13 Nov 2018]. 